\title{
INFECTION OCULAIRE ET GÉNITALE PAR LE VIRUS TRIC
}

Le professeur Barrie R. Jones décrit l'infection oculaire due au virus TRIC (Bedsonia) et suggère que l'application des méthodes exactes pourra démontrer que ce virus est une des causes des infections génitales dites "nonspécifiques" (p. 3).

Il s'agit d'un vieux problème. Le gonocoque décrit en 1879 par Albert Neisser fut le point de départ de l'étude bactériologique de la conjonctivite du nouveau-né, étude que aboutit à la découverte d'une forme non-gonococcique de cette maladie.

D'après l'exemple de la blennorragie on eut alors raison de croire, comme Kroner (1884), que l'infection dériva du canal vaginal de la mère.

Halberstaedter et Prowazek (1907) observèrent les organismes dits "inclusions Halberstaedter-Prowazek" dans la substance cellulaire épithéliale de la conjonctive de malades atteints de trachome; peu après on trouva des inclusions semblables dans les cellules épithéliales conjonctivales d'enfants atteints d'ophtalmie amicrobiale du nouveau-né, dans les frottis urétraux d'hommes atteints d'urétrite non-gonococcique, et dans les frottis génito-urinaires des parents d'enfants atteints d'ophtalmie du nouveau-né. L'inoculation des matériaux obtenus de chaque source produisit la conjonctivite dans les animaux de laboratoire.

Pendant presque 50 ans le progrès fut arrêté faute de pouvoir isoler l'organisme causatif. Cependant, T'ang, Chang. Huang, et Wang (1957) isolèrent un virus de malades atteints de trachome par l'inoculation de frottis conjonctivaux dans les oeufs embryonaires de poulet. Un organisme semblable fut alors isolé de la conjonctive d'un nouveau-né atteint de la blennorrhée à inclusions et du col de l'utérus de la mère d'un autre enfant atteint lui aussi de la blennorrhée à inclusions (Jones, Collier, et Smith, 1959).

Cette méthode de cultiver l'organisme a été appliquée à l'oeil et aux organes génitaux dans une étude coopérative par le professeur Jones, le docteur Al-Hussaini, et le docteur Dunlop, qui rendent compte de leurs expériences dans ce numéro du British Journal of Venereal Diseases (pp. 19 à 42). Ils ont trouvé des inclusions dans les frottis conjonctivaux de 5 enfants atteints d'ophtalmie du nouveau-né et ont isolé le virus chez 3 d'entre eux. Ils ont trouvé des inclusions dans les frottis du col de l'utérus d'une des mères et ont aussi isolé le virus chez cette femme. L'examen de 4 des 5 pères révéla qu'ils étaient tous atteints d'urétrite. Les frottis urétraux prélevés chez 3 des 4 hommes furent tous abactériaux, mais on trouva des inclusions chez les 3 et on isola le virus dans un cas.

Ceci est donc le premier rapport de l'isolation d'un virus de l'urètre du père d'un enfant atteint d'ophtalmie du nouveau-né. Encore plus important est le fait que c'est la première isolation d'un virus chez un malade atteint de ce qu'on aurait nommé "urètrite nonspécifique".

Ces auteurs constatent également que l'infection génitale par le virus TRIC est associée au trachome et aux autres infections de l'oeil par ce virus chez les adultes.

Les futures recherches détermineront le rôle étiologique de cet organisme. En outre elles influenceront notre conception du lymphogranulome vénérien, qui est dû à quelque organisme du même genre; il apparaît que le virus TRIC peut être aussi la cause de la proctite et d'une réaction positive au test fixant le complément du lymphogranulome vénérien.

Il faut se rappeler que depuis le temps de Pasteur le diagnostic qui ne fait que nommer le site d'une infection ne suffit pas; il faut aussi nommer l'organisme qui cause l'infection pour établir un diagnostic complet. Cette importante étude coopérative nous offre le diagnostic exact d'un groupe d'infections génitales nongonococciques dont l'étendue sera precisée par de futures recherches. 